\title{
Memory and meaning in the search for Chinese Australian families
}

\section{Sophie Couchman and Kate Bagnall}

\begin{abstract}
Over the past twenty-five years there has been tremendous interest in researching Chinese Australian family history. This includes documenting the experiences of Chinese migrants and their descendants in Australia from the nineteenth century onwards, as well as seeking to understand their pre-migration lives in China and patterns of return migration. For many Chinese Australian family historians, however, there remains a major difficulty in tracing their Chinese ancestry - not knowing their ancestor's name in Chinese or their precise place of origin beyond the ubiquitous 'Canton'. This essay discusses the endeavours of family historians to uncover their Cantonese roots, including by visiting the qiaoxiang (home village) districts of the Pearl River Delta region in Guangdong province. We reflect on this 'roots tourism' and the practice of personal memory-making in the wake of national and familial forgetting.
\end{abstract}


In 1960, Gwen Num wrote one of the earliest published Chinese Australian family histories, a short article about her father, Daniel Poon Num (1872-1928), which appeared in the journal Nation (Num 1960). Poon Num arrived in Adelaide around the turn of the twentieth century and, joining his elder brother in the fruit and vegetable trade, he soon became a notable figure in the Adelaide Chinese community. He was baptized in the Church of Christ in 1904, took an active part in Chinese community politics and, in 1908, married a white South Australian woman, Gertrude Smith (Num 2010). Nearly sixty years after Gwen Num's article and more than a century after Daniel Poon Num's arrival in Australia, Daniel and Gertrude's grandson Richard visited Qiaotou, a cluster of villages in rural Kaiping county in Guangdong province. Within the family, memory of Poon Num's exact birthplace was lost, but Qiaotou is the likely candidate. Over the course of the nineteenth century, many men of the Poon clan from Qiaotou made their way to southern Australia, settling in Melbourne and across western Victoria to Adelaide.

In Qiaotou, Richard came face to face with his Cantonese heritage, wandering through laneways and past paddy fields, speaking with local villagers and paying his respects at a small village shrine (Figure 1). His visit was made as part of a heritage tour, run by the authors, which gives Australian family historians an opportunity to retrace their Cantonese ancestors' steps through the qiaoxiang counties of the Pearl River Delta region of Guangdong province. ${ }^{1}$ Richard's cousin David had joined us on the tour the previous year, and the cousins' journeys marked a significant moment in their individual searches for their family's Chinese past. After years of tracking ancestors through the Australian archives, sometimes over generations, descendants can be left with an uncomfortable gap in their family narrative following a loss of language, culture and intergenerational memory. Visiting the qiaoxiang can help descendants like Richard and David satisfy an intellectual curiosity and spark their historical imagination, as well as filling an emotional need to understand more about the lives of their ancestors.

\footnotetext{
${ }^{1}$ The term qiaoxiang (僑鄉) refers to the ancestral or home villages of emigrant Chinese and the rural districts in which these villages are found.
} 


\section{<FIGURE 1 ABOUT HERE>}

In this essay, we discuss the endeavours of Chinese Australian family historians in uncovering their Cantonese roots, including by travelling to their ancestral homelands in China, and we reflect on the practice of personal memory-making in the wake of national and familial forgetting. ${ }^{2}$ The family historians we discuss are descended from immigrants from southern China, primarily from Guangdong province, who came to Australia between the 1850s and 1950s; many are of mixed heritage and/or several generations removed from their original migrant ancestors. Growing up in a nation that predominantly celebrates its white British history, these descendants have faced powerful forces of forgetting which have shaped both Australia's national remembering (Hamilton 1994, 23) and their own lives. The twin forces of memory and forgetting are multifaceted, shifting as they pass between the individual and the family, and bending as they are shaped by collective and national memory (Darian-Smith and Hamilton 2013). Descendants' sense of connection to the Chinese language, culture and identity of their ancestors, or their lack thereof, comes from what has been forgotten and what has been remembered - the intergenerational memory passed down through their families. In this essay we present a case study that explores, through the lens of memory and forgetting, the ways that Chinese Australian family historians build new meanings and understandings through genealogical research and 'roots tourism' in China (Li and McKercher 2016; Maruyama and Stronza 2010; Louie 2001). Although their motivations might initially be personal ones - an individual quest to know more about their own ancestry or to address what has been forgotten in their own families - their endeavours also provide a means of overcoming national forgetting through the restoration of historical memory through research in the archives, and the creation of new personal and familial memories through travel in the hometowns of their ancestors.

\footnotetext{
${ }^{2}$ In this essay, we use the terms 'Chinese Australian family historians' to describe people who are researching or descended from at least one Chinese ancestor who lived in Australia. They may not identify themselves as being 'Chinese' or 'Chinese Australian'.
} 


\section{Revealing Chinese Australian family histories}

Although the first known Chinese Australian family was formed in the 1820s (Blomer 1999), stories of such families remained largely untold in the public sphere until the late twentieth century, both overlooked and hidden through the years of White Australia (Bagnall 2011). Before the 1980s there were only a handful of published accounts of Chinese Australian families, prompting Monica Tankey to publish several articles in the early 1980s about the family of her great-grandfather, John Tan Kee (c.1830-1902), who arrived in New South Wales as an indentured labourer from Amoy (Xiamen) in 1851. Tankey issued a rallying cry for further research by Chinese Australian family historians as a means of 'rewriting ... our history books' (Tankey 1981, 195; 1983). Other descendants around Australia were also starting to uncover their families' Chinese pasts, and the shift away from White Australia towards ideas of multiculturalism from the mid-1970s, together with new interests in social and oral history, created an imaginative space for their family stories to be voiced. These early family historians, like those researching Indigenous and convict pasts (Evans 2011; Davison 2000), came to understand that their personal accounts made an important contribution to new ways of viewing Australia's history.

Interest in multicultural and migration histories in the 1980s and 1990s led to projects dedicated to Australia's Chinese history and heritage, including community museums such as the Museum of Chinese Australian History in Melbourne (established 1985), the Golden Dragon Museum in Bendigo (established 1991) and the Northern Territory Chinese Museum (established 1992). Descendants and family historians were among the strongest advocates for these projects, which gave them the opportunity to work with history and heritage professionals in sharing their family stories with a broader public. Capturing personal and intergenerational memories were an important part of this. For example, oral historians Morag Loh, Diana Giese and Janis Wilton recorded interviews with members of the Chinese Australian community (Loh 2012; Wilton 1988; Giese 1997), prompting descendants to speak at conferences, record life stories and publish family histories (e.g. King Koi 1995; Wong Hoy 1999; Hiah and Lee Long 2002). The Museum of Chinese Australian History's 1993 conference on 'Histories of the Chinese in Australasia and the 
South Pacific' (Macgregor 1995) also became a model for subsequent Chinese Australian history conferences - now more than twenty-five in total - which have been multidisciplinary and welcoming of family historians as speakers and audience. Over time, the work of family historians, public historians and academic historians in the field of Chinese Australian history has become deeply entwined, with each enhancing the other (Couchman 2015, 6). ${ }^{3}$

Chinese Australian family historians find great value in connecting with each other. Many are members of their local family history societies, but mainstream groups still largely focus on British and Irish ancestry and so lack the knowledge and resources to help those researching families from other backgrounds. Those researching Chinese ancestors also face particular practical and emotional challenges, including in coming to terms with Australia's complex and confronting history of anti-Chinese laws, policies and ideologies, and consequent losses of family culture and knowledge. To fill the gap, in the early 2000s a number of dedicated Chinese Australian family and community history groups were formed, including Chinese Australian Family Historians of Victoria (CAFHOV) in Melbourne, the Chinese Australian Historical Association in Brisbane (now defunct) and the Chinese Australian Historical Society and the Chinese Heritage Association of Australia, both based in Sydney. These groups provide forums for sharing the challenges and successes of members' research through talks, meetings and publications; their members and others are now also increasingly connecting online, through social media and genealogical websites such as Facebook and Ancestry.

\section{The search for belonging}

The experience of living in a country that excluded Chinese migrants and their descendants from its national memory has resonated through generations of Chinese Australian families, shaping which stories and information have been passed down and which have been forgotten. Sometimes this forgetting has come with the natural progression of time, a

\footnotetext{
${ }^{3}$ This symbiotic historical practice, familiar to many of us working in Chinese Australian history, is now being explicitly discussed and theorized in the work of academic historians (e.g. Evans 2011).
} 
discarding of things no longer relevant, while in other cases it was a deliberate act of erasure of intergenerational identity and memory. The large majority of early Chinese in Australia were men, and many of those who formed Australian families partnered with women of European or Indigenous heritage, who were then largely responsible for the raising of children. In the face of racist sentiments and policies during the White Australia period, and as circumstances permitted, many mixed-race children and grandchildren distanced themselves from their Chinese heritage in a desire to blend in. They changed their names, moved to places where their heritage was unknown, discarded family papers and invented stories to explain "foreign" colouring or to hide gaps in the family story (e.g. Moore 1994). Family photographs were a particular target of this purposeful forgetting, with portraits being destroyed or defaced (Lee 2005, 29; Loh 2012, 119. For families with two Chinese parents, both father and mother, the apparent abandonment or forgetting of language, culture and familial past came about as the result of acculturation and assimilation as they made a life for themselves and their children in a new land (e.g. Cheong 2006, 34; Low Choy 2001). Even when younger generations wanted to know about the family's past, their questions could be deflected (e.g. King Koi 1995). These processes of forgetting began with individuals and flowed across and between generations, the outcome being that many Australian descendants have little or no cultural connection with their Chinese ancestors.

Through their research, Chinese Australian family historians, many of whom grew up in the 1950s and 1960s, look to make sense of fractured family pasts that do not easily fit with the Australian history they were taught as school children or read in history books. Theirs is a search for belonging in a society which, for a century or more, actively discriminated against their ancestors through laws and policies relating to immigration, citizenship, social welfare and employment, among other things. Despite its geographic proximity, for many Australians raised in the White Australia / Cold War era of the mid-twentieth century, China was at best an exotic mystery and at worst a threatening source of Communism, compounding a sense that Chinese immigrants and their descendants were outsiders. For Kevin Wong Hoy, a fourth-generation Queenslander, the place of Chinese as outsiders or 
unwanted immigrants meant that "locating one's place in the history of Australia [could] be an intellectual challenge as well as emotionally confronting” (Wong Hoy 2005, 5). The very records they use to reconstruct their family histories have also been shaped or produced by exclusion and discrimination; for example, ships' passenger lists that give numbers of Chinese passengers but no names, and identity documents issued to under the discriminatory Immigration Restriction Act. Chris Lee, who searched through church records for her grandfather, Anglican missionary James Lee Wah (1832-1909), found the archives steeped in "the attitudes of colonial and racial superiority" and wrote that their absence of emotion was another silencing of Australia's Chinese past (Lee 2005, 22). Confronting historical discrimination in the archives and addressing the absence of Chinese Australians in many published histories gives the work of Chinese Australians family historians a political, as well as an emotional, edge. For many, their quest is more than simply constructing a family tree; it is an effort to understand the historical context of White Australia and earlier anti-Chinese policies, to make sense of mysteries and fractured identities within their families, and to commemorate or recognise the contributions of early Chinese migrants to Australia (e.g. Faulkner 2013; Olsen and Shang 2013). They also seek acknowledgment that they are as Australian as anyone else. Recent mainstream media programs that include Chinese Australian family stories - whether they be from Australia's national broadcaster, the ABC (e.g. Fang 2018; Lee 2018), or commercial television programs like Who Do You Think You Are? - help to validate this position.

\section{Reclaiming lost connections of language and place}

Most Chinese in nineteenth and early twentieth-century Australia came as economic 'sojourners'; their ultimate goal was to return to their families who remained in south China. These men maintained links with their families at home through financial remittances, letters, newspapers and return visits and, were they to die in Australia, they hoped for their bones to be sent back for reburial in their ancestral village. Many, of course, never returned to their homeland, while others oscillated between Australia and China, visiting family, doing business and educating children. Some men eventually brought their 
wives and children to Australia and built new lives and futures here; others still left families they had formed in Australia to return to China in ill-health or old age, effectively disappearing from their children's and grandchildren's lives. The ‘sojourning' tradition of overseas Chinese has been a central theme of Chinese Australian histories (e.g. Rolls 1992), and so family historians learn about the significance and meaning of the ancestral home, and of the ongoing ties between the village and those who went overseas. They trace their ancestors' comings and goings using Australian travel and immigration records, yet they are often left to wonder whether a decision to stay or return was intended or was imposed by circumstance and history. Many also struggle to imagine their ancestors' lives in Guangdong and hope that undertaking research in China will provide answers to family mysteries that Australian archives cannot answer. The realities of genealogical research in China mean that a visit in person to the ancestral village is often the only way to do this. With the Japanese invasion of Guangdong in the late 1930s, the ravages of the Second World War and the closure of mainland China by the Communist Party from 1949, return visits became increasingly difficult for Chinese Australians, and during these tumultuous times many families overseas lost contact with relatives in China. The People's Republic of China remained largely closed off to foreign visitors for more than thirty years, but from the mid-1970s small numbers of Australians began to visit once again to reconnect with family or to experience the land and culture of their ancestors. The qiaoxiang counties of Guangdong were not mainstream tourist destinations, however, and basic tourist needs of transportation, hotels, guidebooks and maps were limited, if not non-existant. The local Overseas Chinese Affairs Office (僑務辦公室 Qiaowu Bangongshi) could assist in facilitating a visit to a home village, if this was known, but many Australians were content with seeing major tourist sights in cities like Beijing and Guangzhou on trips usually organised by the government-run China Travel Service.

Today travel to Guangdong is much easier, yet challenges remain for those seeking to trace their ancestry back to a precise location. Language is perhaps the greatest roadblock. Many descendants, even children of migrant parents, have no or only limited Chinese language 
skills, and they often do not know the name of their ancestor or their home village, both of which are needed to successfully undertake genealogical research in China. This information has not been passed down in many families, and Australian records, such as naturalization applications and marriage registrations, seldom provide enough detail Chinese characters for personal or place names are rare, meaning that it can be hard to reconcile an Australian version of a name with its 'proper' Chinese one. Without an ancestor's name in Chinese characters a descendant is unlikely to locate them in historical Chinese-language newspapers, community records and memorial tablets in Australia, or in genealogies or other records in China. Without the name of the ancestral village they cannot visit their ancestor's Chinese birthplace and former home, their ancestral hall or grave site, nor find their clan and family genealogies (族譜 zupu and 家譜 jiapu), nor further information about their ancestors' origins and life in China.

Chinese Australian family historians work hard to overcome these difficulties. They scour birth, death and marriage certificates, immigration and citizenship records, and the backs of photographs and old envelopes looking for Chinese signatures, addresses, and variations in spellings of names and places. They track down grave sites in Australia which might have Chinese inscriptions, explore business and family connections looking for leads, and speak with family members and elders in the Chinese Australian community hoping for details (e.g. Kehrer 2004). With some information - a possible family names and a possible village name - there are online resources that can help identify and locate the ancestral village, including Chinese genealogy websites and forums (e.g. http://siyigenealogy.proboards.com), maps from Baidu and Google China, and the Roots Villages Database (http://villagedb.friendsofroots.org/search.cgi), a searchable index of clan names and qiaoxiang villages. Despite their best endeavours, however, many family historians still do not succeed, leaving them with a longing to make a tangible connection to China and the pre-migration lives of their ancestors. 


\section{Retracing ancestral journeys - from Australia to Guangdong}

As public historians who have lived in China and worked closely with Chinese Australian family historians over many years (Bagnall 2006, 2013; Couchman 2005), we saw the challenges that family historians faced but also knew of the rich heritage and culture that survives in the Cantonese qiaoxiang towns and villages; we also knew the profound shift in perspective that viewing Australia's Chinese history from south China brings. Kate first lived in Guangdong in the late 1990s, an experience that prompted her interest in Chinese Australian history, and she became keen to try something like the 'In Search of Roots' program, established by Him Mark Lai and Albert Cheng in San Francisco in 1991 (Cheng and Lai 2002), but designed for Chinese Australian family historians, particularly those who were disconnected from their Chinese origins and so could not trace their ancestral village.

We have run a Chinese Australian Hometown Heritage Tour annually since 2017, each time taking a group of around 16 to Hong Kong and Guangdong for about ten days. Participants on the tour have included those who do not know their ancestral village at all, those who know only the county their ancestors came from, and those who know the specific ancestral village or villages. The tour starts in Hong Kong, the port where most early Chinese boarded ships to Australia, before travelling by river ferry to Jiangmen and then by bus through the qiaoxiang districts of Kaiping, Taishan, Xinhui, Zhongshan and Zhuhai. We visit local museums, including those that focus on overseas Chinese history, and spend two days at Cangdong, a UNESCO award-winning heritage project in Kaiping run by Dr Selia Tan of Wuyi University. In Cangdong we learn about village history and architecture, and participate in cultural activities such as cooking, handicrafts and music. We also visit other different kinds of overseas Chinese villages, including the impressive World Heritage-listed diaolou (碉樓; watchtowers) in Kaiping, drawing out Australian connections as we go. Importantly, we work with tour members who know do the name of their ancestral village to organise for them to visit independently or as part of the tour. 
Visiting the qiaoxiang helps Chinese Australian family historians fill emotional and narrative gaps in their family histories and create new memories and cultural knowledge. It is not possible to bring back the family memory that have been lost, but in the qiaoxiang, descendants can trace their ancestors' migration journeys, imagine life for them in their home village, and see the effects, both positive and negative, that 150 years of emigration has had on the local villages, towns and cities. With a better understanding of the complexities of Cantonese history and a greater feel for the culture and language, the Chinese side of Australian family histories is illuminated and personified, as are the experiences of Cantonese families who lost contact with loved ones who went to Australia long ago. One 2017 tour member, Jenny, reflected on her Chinese great great grandfather, saying "suddenly he was a real person", while Megan, who came on the 2018 tour, noted that "while a relative may never have returned as intended, in person or as bones, our journey and our presence signified that overseas family were interested and were returning now". Megan is the great granddaughter of interpreter and storekeeper Chin Kit (18301902), who established his long-term home in Launceston, Australia, and she is yet to find details of his ancestral village in Taishan. She looked on as Richard paid his respects at the village shrine in Qiaotou (Figure 1), and we can perhaps see the empathy of a shared quest and a shared journey reflected in her face at that moment. Megan might not know her precise ancestral home in China, but she came away from the tour with her new memories and understandings of what their lives could have been like.

\section{Conclusion}

The national forgetting of Australia's Chinese past originated in the construction of an imagined white nation where migrant Chinese and Australians of Chinese heritage, including those of mixed race, were excluded and discriminated against. Since the 1980s, Australian family historians have been uncovering the presence and identity of Chinese ancestors and seeking to understand their place in Australian history. These family historians have felt a disconnect between national narratives and family experience, and so have worked alongside history and heritage professionals in forging a space for Chinese 
Australians within Australian public and popular history more broadly. By recovering family memory, enhancing it through research and sharing then their family histories in public, they offer alternatives to national histories that previously excluded their ancestors. Some struggle, however, to overcome the loss of language, culture and intergenerational memory exacerbated by decades of discrimination and marginalization. Severed family connections between Australia and China, and the deliberate or inadvertent loss of knowledge of family information has left some with a profound sense of loss or disconnection. 'Roots tourism' in the form of visiting the qiaoxiang counties of Guangdong, either independently or on a tour like ours, can help overcome gaps in the family story, enabling Chinese Australian family historians to experience, connect and imagine, even if they cannot know for sure.

\section{References}

Bagnall, Kate. 2013. "Landscapes of Memory and Forgetting: Indigo and Shek Quey Lee," Chinese Southern Diaspora Studies 6: 7-24.

—. 2011. "Rewriting the History of Chinese Families in Nineteenth-Century Australia." Australian Historical Studies 42 (1): 62-77.

- 2006. "Golden Shadows on a White Land: An Exploration of the Lives of White Women Who Partnered Chinese Men and Their Children in Southern Australia, 1855-1915." PhD thesis, Sydney: University of Sydney.

Blomer, Valerie. "An Alien in the Antipodes: The Story of John Shying." Self-published. https://web.archive.org/web/20020713123504/http://www.multiline.com.au/ bvl/Stor ies/Shying.htm. Accessed 20 September 2018.

Cheng, Albert, and Him Mark Lai. 2002. "The 'In Search of Roots' Program: Constructing Identity through Family History Research and a Journey to the Ancestral Land'.” In The Chinese in America: A History from Gold Mountain to the New Millennium, edited by Susie Lan Cassel, 293-307. Walnut Creek: Attamira Press.

Cheong, Doreen. 2006. "East-West Fusion.” In From Great Grandmothers to Great Granddaughters: The Stories of Six Chinese Australian Women, edited by Nikki Loong, 31-40. Katoomba: Echo Point Press.

Couchman, Sophie. 2015. "Introduction.” In Chinese Australians: Politics, Engagement and Resistance, edited by Sophie Couchman and Kate Bagnall, 1-21. Leiden: Brill.

— - ed. 2005. Secrets, Silences and Sources: Five Chinese-Australian Family Histories. Melbourne: Asian Studies, La Trobe University.

Darian-Smith, Kate, and Hamilton, Paula. 2013. "Memory and History in Twenty-First Century Australia: A Survey of the Field.” Memory Studies 6 (3): 370-83. 
Davison, Graeme. 2000. "Ancestors: The Broken Lineage of Family History." In The Use and Abuse of Australian History: 80-109. St. Leonards, NSW: Allen \& Unwin.

Evans, Tanya. 2011. "Secrets and Lies: The Radical Potential of Family History." History Workshop Journal 71 (April): 49-73.

Fang, Jason. 2018. "200 Years of Chinese-Australians: First Settler's Descendants Reconnect with Their Roots." ABC Online, 10 June.

https://web.archive.org/web/20181016015635/http://www.abc.net.au/news/2018-0610/first-chinese-settlers-descendants-reconnect-with-their-roots/9845804.

Faulkner, Claire. 2013. Conquest: An Inside Story - The Integration of a Colonial ChineseAustralian Family Cluster. Australia: self-published.

Giese, Diana. 1997. Astronauts, Lost Souls and Dragons: Voices of Today's Chinese Australian in Conversation with Diana Giese. St Lucia, Queensland: University of Queensland Press.

Hiah, Rosalie, and Lee Long, Warren. 2002. "Taking Our Chinese Family History to the Wider Community: Producing the Kwong Sue Duk Family History Video Documentary." In Chinese in Oceania, edited by Pookong Kee, Chooi-hon Ho, Paul Macgregor, and Gary Presland, 77-86. Melbourne: ASCADAPI, Museum of Chinese Australian History, and Centre for Asia-Pacific Studies, VUT.

Kehrer, Jon. 2004. "Honourable Ancestors: My Search for the Chinese Connection." The Ancestral Searcher 27 (4): 328-33.

King Koi, Norma. 1995. "Discovering My Heritage: An Oral History of My Maternal Family - The Ah Moons of Townsville." In Histories of the Chinese in Australasia and the South Pacific, edited by Paul Macgregor, 287-95. Melbourne: Museum of Chinese Australian History.

Lee, Chris. 2005. "Unfolding the Silence: James Lee Wah (1832-1909) Chinese Goldfields Miner and Anglican Missionary." In Secrets, Silences and Sources: Five ChineseAustralian Family Histories, edited by Sophie Couchman, 17-30. Melbourne: Asian Studies, La Trobe University.

Lee, Jane. 2018. "The Story of William Ah Ket, the First Chinese-Australian Barrister." ABC Online, 30 August.

https://web.archive.org/web/20181016020045/http://www.abc.net.au/news/2018-0830/william-ah-ket-the-first-chinese-australian-barrister/10160198.

Li, Tingting Elle, and McKercher, Bob. 2016. "Developing a Typology of Diaspora Tourists: Return Travel by Chinese Immigrants in North America". Tourism Management 56: 106-113.

Loh, Morag. 2012. "Testimonies from White Australia: Oral History Interviews and Chinese Immigrants and their Descendants." The La Trobe Journal 90 (December): $112-71$.

Louie, Andrea. 2001. "Crafting Places Through Mobility: Chinese American 'Roots Searching' in China”. Identities: Global Studies in Culture and Power 8 (3): 343-79. 
Low Choy, Darryl. 2001. “That's Not a Chinese Name.” In Plantings in a New Land: Stories of Survival, Endurance and Emancipation, edited by Chek Ling, 62-78. Brisbane: Society of Chinese Australian Academics in Queensland.

Macgregor, Paul, ed. 1995. Histories of the Chinese in Australasia and the South Pacific. Melbourne: Museum of Chinese Australian History.

Maruyama, Naho, and Stronza, Amanda. 2010. "Roots Tourism of Chinese Americans". Ethnology: An International Journal of Cultural and Social Anthropology 49 (1): 2344.

Moore, Barbara. 1994. "The Case of the Missing Sisters." Ancestral Searcher 17 (2): 6163.

Num, Cora. 2010. 'A Chinese Family In South Australia'. Typescript in possession of the authors.

Num, Gwen. 1960. “A Life with a Difference.” Nation 57 (November): 17-8.

Olsen, Joanne, and Shang, Keith. 2013. With His Gold in a Little Velvet Bag: The Story of a Chinaman and a Bonnie Lassie from Edinburgh. Lindfield, NSW: self-published.

Rolls, Eric. 1992. Sojourners: Flowers and the Wide Sea. St Lucia, Queensland: University of Queensland Press.

Tankey, Monica. 1983. "English on the Outside and Chinese on the Inside." AustraliaChina Review 11 (February): 9-10.

Tankey, Monica. 1981. “A Blueprint for Action.” The Australian Journal of Chinese Affairs 6 (July): 189-95.

Wilton, Janis. 1988. Hong Yuen: A Country Store and its People. Armidale: Multicultural Education Coordinating Committee and Armidale College of Advanced Education.

Wong Hoy, Kevin. 2005. "Chinese-Australian History vs Huaqiao History: Chinese in North Queensland." In Secrets, Silences and Sources: Five Chinese-Australian Family Histories, edited by Sophie Couchman, 3-16. Melbourne: Asian Studies Program, La Trobe University.

—, ed. 1999. Collected Papers on the Yet Foy Family of Queensland. Melbourne: selfpublished. 